\title{
Dissociation of Catch-Up Growth Control and Neural Control of Growth Hormone Secretion in the Stunted Head-Irradiated Rat
}

\author{
H. DAVID MOSIER, JR., REGINA A. JANSONS, KARL F. SWINGLE, AND LYLE C. DEARDEN \\ Departments of Pediatrics, Radiological Sciences, and Anatomy, University of California, Irvine 92717 and the \\ Long Beach Veterans Administration Medical Center, Long Beach, California 90822
}

\begin{abstract}
Male Long-Evans rats were irradiated to the head only at 2 days of age; littermates of the same sex were sham-irradiated. At $\mathbf{4 0}$ days of age the irradiated rats were divided into two groups, one of which was fasted 48 $h$ and the other fed a normal diet. The irradiated rats, fasted and nonfasted, were cannulated in the superior vena cava at 48 to 50 days of age. Between 54 and 58 days of age the cannulated undisturbed rats had blood samples withdrawn at 15-min intervals over an 18 -h period $(9 \mathrm{~h}$ light and $9 \mathrm{~h}$ dark). Body weight and tail length data showed characteristic stunting following irradiation. The superimposed fast caused transient growth retardation; on refeeding, the fasted rats showed a pattern of catch-up growth limited to the irradiated non-fasted body size. Plasma growth hormone (GH) concentration in the fastedrefed rats as compared with the nonfasted irradiated rats showed no change in the average period of the bursts of GH secretion, the numbers of values in ranges of $\mathrm{GH}$ concentration, or the area under the curve of the plasma GH concentration versus time. No difference in these parameters was present in light or dark, considered separately. We conclude 1) that the link between the catch-up growth control and neural mechanisms controlling GH secretion is impaired as a consequence of the neonatal head-irradiation and 2) that catch-up growth acceleration is not dependent on increased GH secretion. (Pediatr Res 20: 261-264, 1986)
\end{abstract}

\section{Abbreviation}

\section{GH, pituitary growth hormone}

X-irradiation of only the head of the 2-day-old rat results in stunting of growth of body weight, tail length, and tibial length (1-6). The mechanism of the abscopal growth stunting is unknown, but we have recently reviewed evidence excluding disturbances of some endocrine functions, including $\mathrm{GH}$ and thyroxine, as possible causes (7). The pattern of growth in the head-irradiated rat is characterized by lack of spontaneous compensatory (catch-up) growth in males and only a slight degree of catch-up growth in females (3). However, the head-irradiated rats are capable of undergoing brisk catch-up growth after a period of starvation. Under those circumstances, catch-up is limited to the smaller body size resulting from the irradiation (7).

Received August 26, 1985; accepted November 5, 1985

Supported by NIH Grant HD 07074.

Address for reprints Dr. H. D. Mosier, Department of Pediatrics, University of California, Irvine, CA 92717.
It is suggested that $\mathrm{GH}$ secretion is linked to the catch-up growth mechanism by the finding of increased $\mathrm{GH}$ levels in sacrificed rat plasma during recovery after transient growth arrest produced by undernutrition $(8,9)$, glucocorticoid treatment $(9)$, or hypothyroidism (10) and of increased pulsatile secretion of GH during recovery after fasting (11) and glucocorticoid treatment (12). The stunted head-irradiated rat appears to have a normal pulsatile pattern of plasma GH concentration and normal average period of bursts of $\mathrm{GH}$ secretion; however, there is an overall reduction in $\mathrm{GH}$ secretion (13). This indicates that either the catch-up growth mechanism is not called into play by the growth stunting of head-irradiation or that the link between the catch-up growth control and the GH releasing mechanism is disturbed as a consequence of effects of irradiation on neural tissue.

The present experiments were designed to determine whether $\mathrm{GH}$ secretion is increased in the stunted head-irradiated rat while the rat undergoes catch-up growth acceleration after a period of fasting. The design permitted a test of two hypotheses: 1) the link between the catch-up growth control and the $\mathrm{GH}$ releasing system is impaired by head irradiation, and 2) catch-up growth acceleration requires increased $\mathrm{GH}$ secretion.

\section{METHODS}

The experiments were carried out on male Long-Evans rats bred from stock obtained from Simonsen Laboratories, Gilroy, CA. The animals were maintained in fresh filtered air, $35-70 \%$ relative humidity, at $21.1-23.3^{\circ} \mathrm{C}$. The daily light/dark cycle was 14/10 h. Purina Lab Chow (St. Louis, MO) and tap water were provided ad libitum. Animal handling and all measurements were carried out by the same individual. Pregnant rats were housed in individual cages and were provided a dustless wood shaving bed from the 14th day of gestation. Litters were reduced to eight pups on the 2 nd day postpartum. The 2-dayold rats were $\mathrm{X}$-irradiated with only the head exposed to the beam as described previously (7). Although the present experiments did not require non-irradiated rats, littermates were routinely sham-irradiated, as previously described (7), in order to confirm effectiveness of the irradiation on growth. At weaning the young rats were transferred to individual cages. During the Ist wk after weaning, the irradiated rats were provided a Petri dish containing a mash of powdered Purina Lab Chow and water in addition to Purina Lab Chow pellets; the mash was changed daily. If an irradiated weanling felt cool to touch during the 1st wk, an equivalent size rat was added to provide warmth or gauze squares were placed in the cage to provide a nest during that week only. Mothers were rested 14 days before rebreeding and were discarded after the fourth litter. Breeder males were discarded at 17 months of age. From 2 days of age, measurements were made at intervals of $1 \mathrm{wk}$ or less of body weight to the 

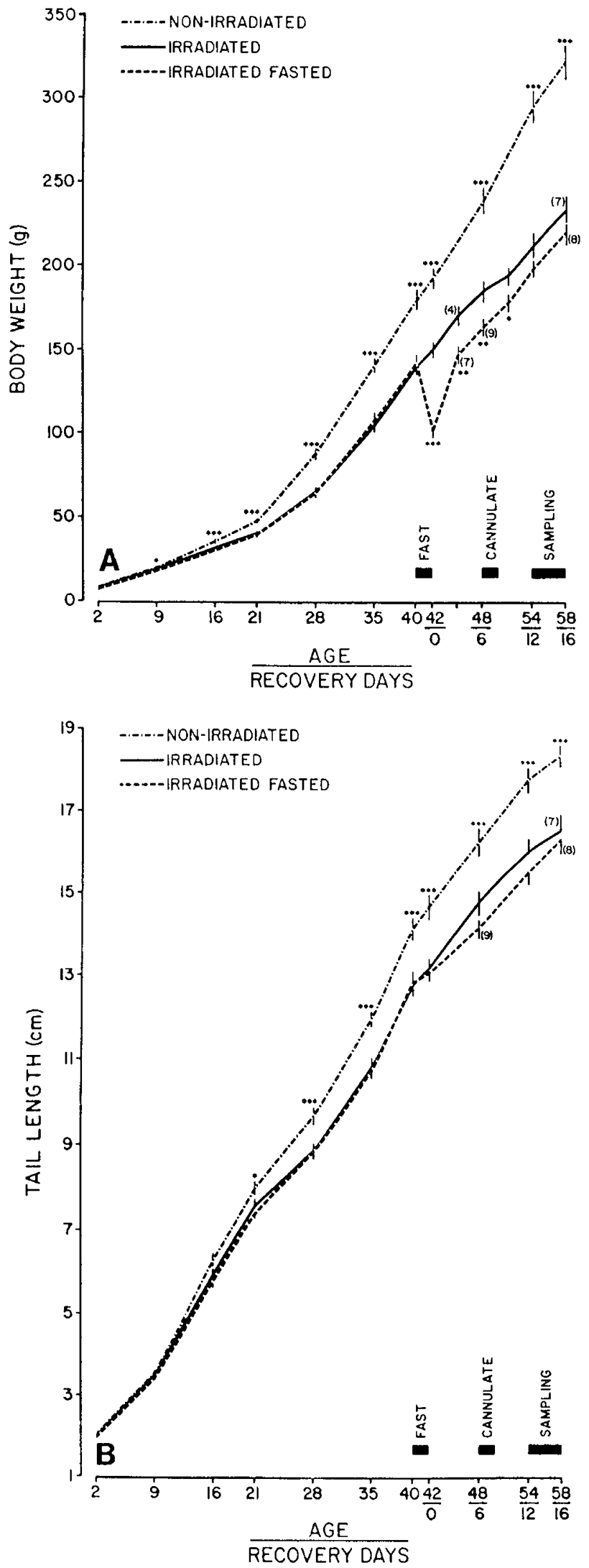

Fig. 1. Growth curves of $(A)$ body weight and $(B)$ tail length of fasted and nonfasted head-irradiated rats and of nonfasted sham-irradiated rats extending from the time of irradiation at 2 days of age through 58 days of age. In irradiated rats compared with sham-irradiated rats, body weight is significantly lower from 9 days of age and the tail length is significantly shorter from 21 days of age. The fasting period $(48 \mathrm{~h})$ is shown by a bar; other bars indicate the range of age of implantation of the cannulas and nearest $0.1 \mathrm{~g}$ and tail length to the nearest $0.1 \mathrm{~cm}$ using the method of De Groot (14).

The experimental groups consisted of 10 irradiated nonfasted rats and 11 irradiated fasted rats. The sham-irradiated group consisted of nine rats. Fasting was carried out by removing food cups for $48 \mathrm{~h}$ beginning at 40 days of age. Tap water was provided ad libitum through this period. At the start of the fast the irradiated rats were separated into the two groups of approximately equal means and variances of body weight.

At 48 to 50 days of age a catheter was implanted into the superior vena cava (15). On two different days prior to the day of sampling, the rats were habituated for $2 \mathrm{~h}$ in insulated chambers (Small Universal Cubical BRS/LVE, Tech Serv Inc., Beltsville, $\mathrm{MD}$ ) provided with fresh air flow and the routine light/ dark cycle. Only one rat was placed in a chamber at a time. Each rat remained in its own storage cage, with food and water, while in the chamber. Actual sampling followed another period of habituation for $3 \mathrm{~h}$. Sampling with replacement of red blood cells from each previous sample was carried out at 15-min intervals. Samples were obtained from $1100 \mathrm{~h}$ through $0500 \mathrm{~h}$ the following day, for a total of $9 \mathrm{~h}$ light and $9 \mathrm{~h}$ dark. Each sampling run was usually carried out on two animals simultaneously, one fasted and one nonfasted.

Plasma $\mathrm{GH}$ was determined in duplicate by radioimmunoassay (8). The initial assay was carried out with a reference range of $10-250 \mathrm{ng} / \mathrm{ml}$. Samples with values above or below that range were reassayed at a plasma concentration corresponding to ranges of $40-1000$ or $1.25-31.25 \mathrm{ng} / \mathrm{ml}$, respectively, in order to determine peak or trough values more precisely. The within assay variation is $4.3 \%$ and the between assay variation is $11.5 \%$ for the last nine assays. All assay runs included samples of experimental rats and simultaneously sampled controls. The area under the curve of plasma $\mathrm{GH}$ concentration plotted against time and the period of $\mathrm{GH}$ surges were determined as previously described (13). Differences between means were tested for significance by one-tailed $t$ test.

\section{RESULTS}

Body weight and tail length. Growth curves from 2 days of age through the completion of the observations are displayed in Figures $1 A$ and $B$. Fasted irradiated rats had a significantly lower weight at the end of the fast than the nonfasted irradiated rats $(102.6 \pm 3.4 \mathrm{~g}$, mean $\pm \mathrm{SE}$, in fasted rats versus $150.0 \pm 4.5 \mathrm{~g}$ in nonfasted rats, $p<0.005$ ). During recovery from fasting the mean weights of the fasted irradiated group remained significantly below that of the nonfasted irradiated group at 7 and 14 days; thereafter, no significant differences were observed although body weight in fasted irradiated rats was less than that of nonfasted irradiated rats through that period. Tail length growth appeared to slow in the fasted irradiated group during the 1 st wk of recovery. At 7 days recovery the lengths were $14.1 \pm 0.2 \mathrm{~cm}$ in fasted irradiated rats versus $14.7 \pm 0.3$ in nonfasted irradiated rats, but the level of significance was only $p<0.1$. Beyond $2 \mathrm{wk}$ of recovery, the number of animals in each group were depleted due to sacrifice following sampling runs. The patterns of growth, however, in the fasted and nonfasted irradiated groups and in the sham-irradiated groups were representative of those established with larger numbers of animals and a longer period of recovery in a previous study (7). There was no mortality during the fast.

$G H$. Both the nonfasted and the fasted irradiated groups displayed normal pulsatile patterns of plasma GH concentration. The periodicity of clustered bursts of $\mathrm{GH}$ secretion was not

of blood sampling. The points on the growth curves represent data of nine sham-irradiated rats, 10 irradiated nonfasted rats, and 11 irradiated fasted rats, except as indicated by numbers in parentheses. Levels of significance are shown as follows: ${ }^{*} p<0.05 ;{ }^{* *} p<0.01 ;{ }^{* * *} p<0.005$. 
Table 1. Number of values of $G H$ concentration in plasma occurring within arbitrarily designated ranges in fasted and nonfasted head-irradiated rats (mean $\pm S E$ )

\begin{tabular}{|c|c|c|c|c|c|}
\hline \multirow[b]{2}{*}{ Groups } & \multicolumn{5}{|c|}{ Ranges of $\mathrm{GH}$ concentration $(\mathrm{ng} / \mathrm{ml})$} \\
\hline & $50-99$ & $100-199$ & $200-499$ & $500-999$ & $>1000$ \\
\hline \multicolumn{6}{|l|}{ Light and dark } \\
\hline Nonfasted & $5.2 \pm 0.6$ & $5.5 \pm 1.1$ & $3.7 \pm 1.1$ & $1.3 \pm 0.5$ & $0.5 \pm 0.3$ \\
\hline Fasted & $4.5 \pm 0.8$ & $4.6 \pm 0.6$ & $4.1 \pm 0.8$ & $1.3 \pm 0.2$ & $0.7 \pm 0.3$ \\
\hline$p$ & NS & NS & NS & NS & NS \\
\hline \multicolumn{6}{|l|}{ Light only } \\
\hline Nonfasted & $2.3 \pm 0.5$ & $2.9 \pm 0.7$ & $2.3 \pm 0.8$ & $0.7 \pm 0.3$ & $0.3 \pm 0.2$ \\
\hline Fasted & $2.6 \pm 0.5$ & $1.9 \pm 0.3$ & $2.0 \pm 0.5$ & $1.0 \pm 0.2$ & $0.5 \pm 0.2$ \\
\hline$p$ & NS & $<0.1$ & NS & NS & NS \\
\hline \multicolumn{6}{|l|}{ Dark only } \\
\hline Nonfasted & $2.9 \pm 0.4$ & $2.6 \pm 0.6$ & $1.4 \pm 0.3$ & $0.6 \pm 0.2$ & $0.2 \pm 0.1$ \\
\hline Fasted & $1.9 \pm 0.5$ & $2.7 \pm 0.5$ & $2.1 \pm 0.4$ & $0.3 \pm 0.2$ & $0.3 \pm 0.1$ \\
\hline$p$ & $<0.1$ & NS & $<0.1$ & NS & NS \\
\hline
\end{tabular}

Table 2. The area under the curve of $G H$ concentration vs time in fasted and non-fasted head-irradiated rats expressed as units/interval (mean $\pm S E)$

\begin{tabular}{llll}
\hline Experimental groups & $n$ & $\begin{array}{c}\text { area } \\
\text { (U/interval) }\end{array}$ & $p$ \\
\hline $\begin{array}{l}\text { Combined light and dark } \\
\text { Nonfasted }\end{array}$ & 10 & $56.4 \pm 11.4$ & NS \\
$\quad$ Fasted & 11 & $63.7 \pm 9.0$ & \\
& & & \\
Light & 10 & $62.3 \pm 10.7$ & NS \\
$\quad$ Nonfasted & 11 & $72.1 \pm 12.1$ & \\
$\quad$ Fasted & & & \\
& & & NS \\
Dark & 10 & $51.7 \pm 12.8$ & \\
$\quad$ Nonfasted & 11 & $54.9 \pm 7.7$ & \\
$\quad$ Fasted & & & \\
\hline
\end{tabular}

significantly different between the two groups. The periods were $3.24 \pm 0.17 \mathrm{~h}$ in nonfasted irradiated rats and $3.25 \pm 0.12 \mathrm{~h}$ in fasted irradiated rats.

The number of peak values of $\mathrm{GH}$ concentration in arbitrarily designated ranges of concentration, 50-99, 100-199, 200-499, $500-999$, and 1000 or more $\mathrm{ng} / \mathrm{ml}$, were counted. There were no significant differences between means of these ranges for all data (light and dark combined) or for light and dark periods considered separately (Table 1 ).

The area under the curve of $\mathrm{GH}$ concentration plotted against time was not significantly different between the nonfasted irradiated rats and the fasted irradiated rats for light and dark combined or light and dark considered separately (Table 2).

\section{DISCUSSION}

In the present experiments, no difference occurred in the average period of surges of $\mathrm{GH}$ secretion, amplitude of $\mathrm{GH}$ secretion, and area under the curve of plasma $\mathrm{GH}$ concentration versus time during the recovery period after a fast in stunted head-irradiated rats as compared with nonfasted irradiated rats. No difference was found when the data from light or dark periods were viewed separately.

Previously we have shown that GH secretion is increased during the recovery period after a fast in intact (nonirradiated) rats suggesting that $\mathrm{GH}$ secretion may be linked to the catch-up control and, in addition, may be part of the mechanism responsible for catch-up growth acceleration $(8,9)$. We have also found increased GH secretion in the glucocorticoid-treated rat $(9,12)$.
Catch-up growth does not occur in the glucocorticoid-treated rat, but this has been attributed to other defects, including long lasting alteration of food efficiency (18) and persistent defects in cartilage structure (19) and function (20) which might interfere with the catch-up growth process in that model. Recently, we have shown that the stunted head-irradiated rat undergoes catchup growth acceleration during refeeding after a period of starvation. Thus the present results indicate that the link between catch-up growth control and $\mathrm{GH}$ release is impaired as a consequence of the irradiation. They also provide evidence that catchup growth is not dependent on increased GH secretion.

We have previously found that the increased growth hormone secretion in the fasted-refed rat takes place during the diurnal light phase (11) which corresponds to the inactive phase of the rat (21). That no difference occurred in either light or dark in the present study is further evidence for a dissociation between the catch-up control and GH secretion. The data also exclude the possibility that a shift in the total amount of $\mathrm{GH}$ secreted might have occurred between the light and dark phases leaving the mean of combined area measurements unchanged.

The present values for area under the curve of GH concentration plotted against time closely match those previously found for stunted head-irradiated rats maintained on stock diet ad libitum (13). In that study it was shown that the mean area for the combined data from light and dark periods was significantly less in irradiated rats than in their sham-irradiated littermates $(64.9 \pm 6.4$ versus $91.7 \pm 10.7$ area U/interval, mean $\pm \mathrm{SE}$, respectively). Previous experiments have indicated, however, that GH deficiency may not be the cause of the growth failure after neonatal head-irradiation of the rat. Treatment with $\mathrm{GH}$, alone or combined with thyroxine, failed to improve the growth rate in the head-irradiated rat (3). Tibial epiphyseal width in irradiated rats was found to be normal at 70 days of age (7) instead of narrowed as one would expect in GH deficiency (22). We have found no difference in bioassayable somatomedin activity, a GH-dependent factor (23), between irradiated and control rats (Wright JC, Mosier HD Jr, unpublished data). Total cell number in heart, liver, kidney, and skeletal muscles was not significantly reduced in stunted head-irradiated rats at 21-22 days (13); hypopituitarism, on the other hand, would be expected to result in reduced cell number (24). The present evidence that the stunted head-irradiated rat is able to undergo catch-up growth acceleration without increasing $\mathrm{GH}$ secretion provides additional evidence that the head-irradiated rat is small for reasons other than a lack of $\mathrm{GH}$.

The stunted head-irradiated rat may be a particularly useful model for the study of the mechanism controlling catch-up growth because in this preparation $\mathrm{GH}$ secretion does not appear 
to covary with catch-up growth acceleration and yet it has an apparently normal rhythmic secretory pattern. Although the mechanism responsible for catch-up growth is unknown, an attractive conceptual model for catch-up growth involving a central control has been proposed by Prader et al. (25) and Tanner (26) involving a sensor for body size, a set-point for normal body size for age, and a mechanism for altering growth rate. On the basis of findings in the head-irradiated rat we have proposed that the putative set-point is reset for a smaller body size and that the remaining elements of the control, i.e. sensor of body size and stimulator of growth acceleration, function normally (13).

Acknowledgments. Purified rat $\mathrm{GH}$ and the first antibody were provided by the Pituitary Hormone Distribution Program, NIADDKD.

\section{REFERENCES}

1. Yamazaki JN, Bennett LR, Mc Fall RA, Clemente CD 1960 Brain radiation in newborn rats and differential effects of increased age: I Clinical observations. Neurology 10:530-536

2. Yamazaki JN, Bennett LR, Clemente CD 1962 Behavioral and histologic effects of head irradiation in newborn rats. In: Haley TJ, Snyder RS (eds) Response of the Nervous System to Ionizing Radiation. Academic Press, New York, pp 57-73

3. Mosier HD Jr, Jansons RA 1967 Stunted growth in rats following X-irradiation of the head. Growth 31:139-148

4. Mosier HD $J_{r}$, Jansons RA 1971 Allometry of body weight and tail length after head X-irradiation in rats. Growth 35:23-31

5. Saković NV 1969 Effect of local irradiation of the head of 2-day old rats: Morphological and functional disorders and genetic changes in their progeny. In: Sikov MR, Mahlum DD (eds) Radiation Biology of the Fetal and Juvenile Mammal. US Atomic Energy Commission, Division of Technical Information, Publication CON-690501, Oak Ridge, TN, pp 453-474

6. Mosier HD Jr, Sondhaus CA, Dearden LC, Zuniga OF, Jansons RA, Good CB, Roberts RC 1983 Cartilage metabolism during growth retardation following irradiation of the head of the neonatal rat. Proc Soc Exp Biol Med 172:99-106

7. Mosier HD Jr, Good CB, Jansons RA, Sondhaus CA, Dearden LC, Alpizar-S $\mathrm{M}$, Zuniga OF 1983 The Effect of neonatal head-irradiation and subsequent fasting on the mechanisms of catch-up growth. Growth 47:13-25

8. Sinha YN, Wilkins JN, Selby F, VanderLaan WP 1973 Pituitary and serum growth hormone during undernutrition and catch-up growth in young rats. Endocrinology 92:1768-1771

9. Mosier HD Jr, Jansons RA 1976 Growth hormone during catch-up growth and failure of catch-up growth in rats. Endocrinology 98:214-219

10. Mosier HD Jr, Dearden LC, Jansons RA, Hill RR 1977 Growth hormone, somatomedin and cartilage sulfation in failure of catch-up growth after propylthiouracil-induced hypothyroidism in the rat. Endocrinology 100:1644-1651

11. Mosier HD Jr, Jansons RA, Dearden, LC 1985 Increased secretion of growth hormone in rats undergoing catch-up growth after fasting. Growth 49:357364

12. Mosier HD Jr, Jansons RA 1985 Increase in pulsatile secretion of growth hormone during failure of catch-up growth following glucocorticoid-induced growth inhibition. Proc Soc Exp Biol Med 178:457-461

13. Mosier HD Jr, Jansons RA, Swingle KF, Sondhaus CA, Dearden LC, Halsall LC 1985 Growth hormone secretion in the stunted head-irradiated rat. Pediatr Res 19:543-548

14. De Groot DA 1963 Tail growth in the thyroxine-treated hypophysectomized rat as a sensitive criterion for growth hormone activity. Acta Endocrinol (Copenh) 43:423-431

15. Tannenbaum GS, Martin JB 1976 Evidence for an endogenous rhythm governing growth hormone secretion in the rat. Endocrinology 98:562-570

16. Mosier HD Jr, Jansons RA 1970 Effect of X-irradiation of selected areas of the head of the newborn rat on growth. Radiat Res 43:92-104

17. Mosier HD Jr, Jansons RA, Biggs CS, Tanner SM, Dearden LC 1980 Metabolic clearance rate of growth hormone during experimental growth arrest and subsequent recovery in rats. Endocrinology 107:744-748

18. Mosier HD Jr 1972 Decreased energy efficiency after cortisone induced growth arrest. Growth 36:123-131

19. Dearden LC, Mosier HD Jr 1972 Long term recovery of chondrocytes in the tibial epiphyseal plate in rats after cortisone treatment. Clin Orthop 87:322331

20. Mosier HD Jr, Jansons RA, Hill RR, Dearden LC 1976 Cartilage sulfation and serum somatomedin in rats during and after cortisone-induced growth arrest. Endocrinology 99:580-589

21. Richter CP 1922 A behavioristic study of the activity of the rat. Comp Psychol Monog 1:1-55

22. Evans HM, Simpson ME, Mark W, Kibrick E 1943 Bioassay of the pituitary growth hormone. Width of the proximal epiphyseal cartilage of the tibia in hypophysectomized rats. Endocrinology 32:13-16

23. Daughaday WH 1981 Growth hormone and the somatomedins. In: Daughaday WH (ed) Endocrine Control of Growth. Elsevier, New York, pp 1-24

24. Winick M, Grant P 1968 Cellular growth in the organs of the hypopituitary dwarf mouse. Endocrinology 83:544-547

25. Prader A, Tanner JM, von Harnack GA 1963 catch-up growth following illness or starvation. J Pediatr 62:646-659

26. Tanner JM 1963 The regulation of human growth. Child Dev 34:817-847 